\title{
Erratum to: Assessment of myocardial injury after reperfused infarction by $T 1 \rho$ cardiovascular magnetic resonance
}

Rutger H. Stoffers ${ }^{1,2+}$, Marie Madden ${ }^{1 \dagger}$, Mohammed Shahid ${ }^{1}$, Francisco Contijoch ${ }^{2}$, Joseph Solomon ${ }^{1}$, James J. Pilla', Joseph H. Gorman $\|^{2}$, Robert C. Gorman ${ }^{2}$ and Walter R. T. Witschey ${ }^{1 *}$

\section{Erratum}

In the original version of this article [1], published on 15 February 2017, the author names were incorrectly displayed.

Originally the author names have been published as:

- Joseph H. Gorman

- Robert C. Gorman III

The correct author names are:

- Joseph H. Gorman III

- Robert C. Gorman

The original publication of this article has been corrected. The publisher apologizes to the readers for the inconvenience caused.

\section{Author details}

'Department of Radiology, Perelman School of Medicine, University of Pennsylvania, 1 Silverstein 3400 Spruce Street, Philadelphia, PA 19104, USA.

${ }^{2}$ Gorman Cardiovascular Research Group, University of Pennsylvania,

Philadelphia, PA, USA.

Published online: 27 March 2017

\section{Reference}

1. Stoffers, et al. Assessment of myocardial injury after reperfused infarction by T1 $\rho$ cardiovascular magnetic resonance. J Cardiovasc Magn Reson. 2017;19:

17. doi:10.1186/s12968-017-0332-z.

\footnotetext{
* Correspondence: witschey@mail.med.upenn.edu

${ }^{\dagger}$ Equal contributors

${ }^{1}$ Department of Radiology, Perelman School of Medicine, University of

Pennsylvania, 1 Silverstein 3400 Spruce Street, Philadelphia, PA 19104, USA

Full list of author information is available at the end of the article
} 